\title{
The Traditional Evolution of Style and Especially of Color of Bridal Dresses in Different Cultures during the Centuries
}

\author{
Arvanitidou Zoi \\ PhD Candidate in Folklore. University of the Aegean \\ Arvanitidou@aegean.gr
}

Gasouka Maria

Assistant Professor in Folklore and Gender, University of the Aegean

Doi:10.5901/jesr.2014.v4n4p264

mgasouka@rhodes.aegean.gr

\begin{abstract}
The wedding is celebrated with the most formalized ceremonies. The bridal dress is a particularly important and symbolic object during modern wedding ceremonies that communicates so much about the customs of marriage, but also the personality, the femininity and the sexuality of the wearer as well as the social conventions. Many people consider the cultural traditions unchanged from generation to generation, but those concerning the wedding dress are not static, or unchanged. The styles and colors of the bridal dress have changed depending on the fashions of the era, the cultural influences and circumstances of the marriage. The "Traditional" white wedding dress as we know it today in Europe and North America is not very old, as it was worn just 150 years ago during the mid of 18th century. The first one was worn by Queen Victoria in 1940. Before the white gown, the bridal dress followed the concurrent silhouettes and colors of day dresses and the whites of the time were probably in cream or ivory shades. The brides of royal families wore heavy brocaded gowns and the red color was a very popular one in Western Europe. During the interwar years a gradual shift towards the style of the evening wear and the pure white bridal dress was established. After 1934, when the church had allowed the celebration of weddings during the afternoon, the opportunity for evening receptions was given, influencing the style and colors of wedding dresses. Hollywood movies also had a major impact in the formation of the style and the change of its color.
\end{abstract}

Keywords: Wedding dress, Culture, Colors, Identify, Femininity

\section{Introduction}

People celebrate the transition from one life stage to the next. The wedding is celebrated with the most formalized ceremonies. The bridal dress is a particularly important and symbolic object during modern wedding ceremonies that communicates so much about the customs of marriage, but also the personality, the femininity and the sexuality of the wearer as well as the social conventions. Many people consider the cultural traditions unchanged from generation to generation, but those concerning the wedding dress are not static, or unchanged. The styles and colors of the bridal dress have changed depending on the fashions of the era, the cultural influences and circumstances of the marriage. The "Traditional" white wedding dress as we know it today in Europe and North America is not very old, as it was worn just 150 years ago during the mid of 18th century. The first one was worn by Queen Victoria in 1940. Before the white gown, the bridal dress followed the concurrent silhouettes and colors of day dresses and the whites of the time were probably in cream or ivory shades. The brides of royal families wore heavy brocaded gowns and the red color was a very popular one in Western Europe. During the interwar years a gradual shift towards the style of the evening wear and the pure white bridal dress was established. After 1934, when the church had allowed the celebration of weddings during the afternoon, the opportunity for evening receptions was given, influencing the style and colors of wedding dresses. Hollywood movies also had a major impact in the formation of the style and the change of its color. A certain color has different meanings in different cultures. So, in Asian countries red is considered the color of happiness and is dominant in wedding dresses while white is the color of mourning for the followers of Confucianism. When Japan brides wore white kimono at their weddings, it symbolized the separation from their birth family. In other countries other colors are dominant like green in Hungary, which is excluded in Britain, particularly in Scotland testifying that everything is based on the cultural context. 


\section{Symbolic Meanings of Bridal Dress and Its Colors}

The socially constructed ritual of marriage is charged with the prevailing cultural concepts and conventions and the bridal dress is a highly symbolic object on this show and on the presentation of the femininity and the sexuality of the bride. Marriage as a rite of passage marks the separation of the bride from her parental family and the formation of a new one and the validation (social approval) of the couple's sexual relationships on the condition that they will create descendants. The style and the color of the wedding dress are determined by the contextual factors of each wedding, the social conventions and the cultural context. It contains obvious and latent symbolisms which are communicated between the bride and the wedding attendees (Walsh, 2005).

The white color of the wedding dress, in the Western world, traditionally symbolizes purity and virginity. These concepts, which have their roots in the pre-Victorian era, even today are wrong, as they are no longer associated with the value of the bride as a woman. The style and color are chosen by each bride reflect her personality, her relationship with her body, her sexuality and her attitude towards marriage. The bride with her wedding dress shows her attitude towards tradition. If she chooses the white color, except from the implied mental purity she also declares that she agrees with the accepted traditional wedding wear, while if she chooses another color, she makes a strong statement about her personality, although sometimes it is expressed in a way that may not be acceptable from all the invitees. The coded messages contained in a wedding dress are communicated to all the wedding invitees in a similar way although the perception of some people of these messages may differ or the perceived meanings may differ from person to person.

The wedding dress symbolizes the basic or princely perfection. When a woman expresses the desire to feel like a princess on her wedding day, she wishes to acquire the enchanting beauty of a princess or a goddess. When she feels that day she is in a special and superior spiritual state, which leads to a transformation, her wedding dress is not just an artifact that contributes to the "perfect" look but it is an amulet that helps this transformation (Paul, 2000).

Many women reveal today that they are almost ashamed because they succumb to the standard model and in reality they do not want to wear a traditional white wedding dress. With this statement they reveal a latent internal conflict related to the connotations of the white color as a symbol of virginity as most of them are no longer virgins when they get married. Especially feminists feel that there is a conflict between tradition and their feministic beliefs (McBride-Mellinger, 1993). Nevertheless, there is a strong desire for a white wedding dress as it constitutes the archetypal symbol of marriage. Historically, the white bridal dress symbolizes the end of an individual woman's life and the beginning of her role as a dependent spouse. Nowadays it does not mark the death of individuality but of singlehood and points the start of a mature partnership. The bridal dress is a deep archetypal way of identifying the breakaway from the bride's previous life. Even the white gown might symbolize the innocence of childhood and the irresponsibility and carelessness that a woman relinquishes during her wedding day (Paul, 2000).

\section{The Role of the Bride in the Creation of Her Wedding Dress}

The bride is the main character of the wedding ceremony and assumes this role from the day that her wedding dress is created as she decides what to wear, constituting a means of negotiation and compromise with her immediate social environment, which is actively involved in the design of her wedding gown (Walsh, 2005).

The design of the bridal dress and the selection of its color is exclusively a female affair. The bride has the primary responsibility for this selection, but other female members of the family, like her mother, her mother in law, her sisters and sometimes her bridesmaids are also involved. Each of the women mentioned above (the social environment of the bride and the bride) have their own perception about the perfect wedding dress and when these perceptions differ powerful conflicts arise. The choice of the wedding dress' features allows the bride to present her personality within the limits and the conventions of marriage. There is quite a large freedom of choice in the field of bridal gowns which allows the individual expression within the strict protocol of the wedding ceremony and this is a unique female privilege. The bride is the center of everyone's attention and her dress is under criticism or praise, depending on how well she represented her personality and femininity according to the perception of the attendees (Walsh, 2005).

\section{The Contemporary Evolution of the Style and the Color of the Wedding Dress}

There are many "sayings" about the customs of marriage and perhaps the most notorious for the wedding dress is the one that it must contain: "something old, something new, something borrowed and something blue" (Walsh, 2005). Similarly the following poem advises brides for the appropriate colors of their bridal dresses and which they should avoid: 


\author{
Married in blue, love ever true, \\ Married in white, you've chosen right, \\ Married in red, you'll wish yourself dead, \\ Married in black, you'll wish yourself back, \\ Married in gray, you'll go far away, \\ Married in brown, you'll live out of town, \\ Married in green, ashamed to be seen, \\ Married in pink, of you only he'll think, \\ Married in pearl, you'll live in a whirl, \\ Married in yellow, jealous of your fellow \\ (Emrich 1970:18)
}

Before the 1800s, brides wore black or dark wedding dress. Until 1840 the brides in Europe and North America wore wedding dresses in various colors like blue, yellow and "practical" colors like black, gray or brown. Before Queen Victoria, brides, in Western Europe, who were royal family members, wore red, heavily brocaded gowns (Otnes \& Pleck, 2003). In the Victoria \& Albert Museum there are two wedding dresses of the 18th century which seems that were they intended for the presentation of the bride after the wedding in the royal court. They are made of silk fabric, embroidered with silver and colored threads and as the light reflects on their surface, it creates impressive reflections. The King approved silver decorations on wedding dresses, but their high cost was something that only the very wealthy families could afford. The first one is from the marriage of the 5th Earl's of Devon daughter in May 1747. The second one is from the end of 1770 and it is made from pure, silk, white satin in evening gown style, suitable for a evening, private wedding ceremony with high profile guests. Researchers have yet to trace its origin but its quality and color have led them to these assumptions (Ehrman, 2011).

Ordinary mortal women, when they chose the "white" color, they did not choose pure white but cream or ivory, because it flattered their skin. As for the style of the wedding dress, it followed that of the daily clothing which had a high neck, closed neckline and long sleeves and that is because in Great Britain marriages took place in the early hours until 1886 (Monger, 2004). The marriage of Queen Victoria, in 1840 marked the beginning of "the tradition" of the white wedding dress. The shockingly simple white wedding dress was a marked deviation from the rule that wanted the royal wedding dresses decorated with precious stones. Similarly, the daughter of Princess Alice and the Princess of Wales got married in white wedding dresses in 1858 and 1863 respectively. Of course these royal weddings influenced the preferences of ordinary mortals (Olian, 1994).

The white wedding dress did not prevail immediately. The black silk taffeta bridal dress of Maggie Scott Wilson in 1881 is preserved as well as the brown silk dress of the Vaughan family from 1894. The brides of the upper social classes usually wore white wedding gowns, while those of the working class wore a "new" dress in various practical colors that could be also worn during other circumstances apart from the wedding day in contrast to the white dressing gown that was worn only once. (Historic Costume \& Textiles Collection, 1998). The white wedding dress gave to the bourgeoisie an opportunity for conspicuous consumption as it showed that the bride's family was so rich, so that the bride could choose an expensive elaborate dress that would be worn only once, as it could be damaged in any other use (Ingrassia, 2007). When there was mourning, the bride wore a black, gray or purple wedding dress. After 1886 the British church allowed the marriages in the afternoon and many women choose to wear practical costumes. Subsequently the etiquette books turned this practice of the white wedding dress into tradition (Howard, 2008).

The rise of the standard of living during the 20th century imposed a modification of the tradition and the practice of the wedding dress to be worn only once, while during the 19th century it was very possible that the wedding dress would be worn more often (Howard, 2008). The historic and romantic years of Hollywood have raised shiny white evening dresses that influenced the designs of wedding dresses (Historic Costume \& Textiles Collection, 1998), while after 1945 they helped to crystallize the "white wedding" and gave to it a form of regulatory nature (Martin, 2011). During the midwar period, the style and decoration of the wedding dresses gradually followed the style of the evening wear, and the daily dressing became more practical, informal and androgynous. The shades of white and cream dominated the 1920s, the pale gold and pink and the decorations with metal threads and lace were fashionable. During the uncertain years of recession after 1930, the classic white satin returned, but after 1935 the pastel colors reappeared (Ehrman, 2011).

After 1940, the pure white bridal dress was permanently established and prevailed to be worn exclusively during the wedding day and it was especially made for the wedding ceremony. The Second World War brought about some changes in the style of the wedding dress. Brides, by necessity, as the wedding was planned in a very short time, which depended on the leave of absence of the groom from the army, practically wore suits or short, daily dresses. During this 
period there was also plenty of silk parachute cloth, which served as the main material for the wedding dresses. Katá tฤv

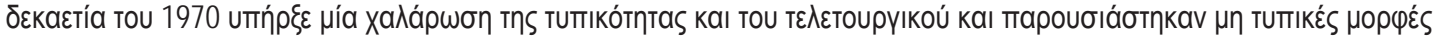

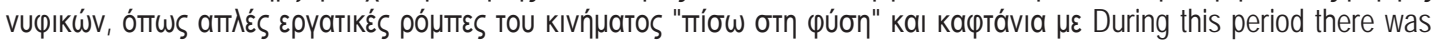
also plenty of silk parachute cloth, which was served as a main material for the wedding dresses. During the 1970s there was a relaxation of the formality of the wedding ritual and atypical wedding dresses were presented such as simple robes and caftans with hoods (Historic Costume \& Textiles Collection, 1998). The "white" wedding dress got a strong boost in 1981 after the wedding of Prince Charles with Lady Dianna Spencer. She wore a white bridal dress from taffeta with a tail length of 25 feet and one in six people worldwide watched their marriage on TV. Dianna's wedding dress is considered the epitome of the traditional white wedding dress.

\subsection{Other Colors of Wedding Dress in Western Civilization}

In 2010 the Australian Michelle Murray wrote the play "The Black Wedding Dress". During her research for this project she found out that the white wedding dress was not affordable for most of the women of the Australian mainland until recently. The dark dresses were preferred because they could be worn again as "good" dresses, while black was the ordinary color of the wedding dress for young women who got married to widowers. In Hahndorf Academy in South Australia, Murray found out a black, skintight dress, attached with a white veil, which represents the German Lutheran marriage tradition. Its symbolism was to "prepare" the bride for her wedding deprivation. The title of the project "The Black Wedding Dress" is a reversal of the idealized female travel and is a mythical story of survival and adaptation to difficult conditions: The protagonist, a young woman from the Victorian era, gets pregnant by her Aboriginal lover and escapes from a violent marriage and following him in the desert, she says: "I am a white woman who got married to a black man, in a black wedding dress. The white wedding dress, which came one day after the wedding, could not tell my story, as a black one can". The writer herself got married in a very dark green dress, so dark that it looked black (Murray, 2011).

Another color that makes a strong declaration of independence is red. There are two examples of known women who got married in a red dress. Monica Maurice, an independent, unconventional woman, the first woman - member of the association of mining electrical engineers, in her wedding ceremony in June 1938, wore a ruby red, silk dress. Even the economist Rachel Ginsburg, who got married in a synagogue at London in January 1949, chose a red woolen suit in the "New Look" style, which was launched by Christian Dior in 1947. Her mother found it quite bold, but her father and her future husband agreed with her choice. These two examples provide a strong contrast of the popular image of young brides in virginal white popularized by the media and the films of Hollywood. Such vivid colors make a bold statement about the personality of the bride (Ehrman, 2011).

\section{The Colors of Wedding Dress in Non-Western Cultures}

For many non-Western cultures, red is the traditional color of the wedding dresses. They are worn by Hindu and Muslim brides, as well as Chinese and Vietnamese for whom this is the color of good luck. It is used in many Asian countries as well as in Indonesia, where unlike the West, the traditional white represents mourning and death. The traditional Korean wedding dress imitated the costume of princesses and consisted of a red skirt and yellow jacket, over long pants. Above them, brides worn a red robe with wide sleeves with stripes in various colors. Since the 1980s the western bridal styles have prevailed, but nowadays brides use both styles (Historic Costume \& Textiles Collection, 1998). In Japan, before the Second World War, the usual wedding dress was a black long-sleeved kimono. Since 1960, it was replaced by a white uchikake, elaborately decorated, that was worn over a plain white kimono which symbolized the mourning for her separation from the paternal family. Since 1980 the white western style wedding dress prevailed in these countries also (Suga, 2003).

The traditional Palestinian dress imitated a royal dress (thob malekeh) but it was replaced by Western-style wedding dresses, from the 1900 in urban ares and from the 1930 in rural ones. Today, a modern version of the traditional Palestinian wedding dress is worn at some weddings as a confirmation of the bride's cultural identity. In many other countries, the renewed interest in national identity, popularized the traditional wedding costumes. Even many African Americans incorporate elements from their cultures from West Africa in their wedding ceremonies as authentic traditional clothing and accessories, or cloth of kente or asooke, with which they manufacture western style wedding dresses (Seng \& Wass, 1995).

The wedding dresses in rural areas were not made from precious materials such as silk, but their decor was very elaborate and so that was the declaration of wealth of the family of the bride. Often the embroidery and decoration was done by the bride herself and they decorated the dress with precious metals and gold coins (Seng \& Wass, 1995). The 
wedding ceremonies, in some cultures, last several days and people in them make several costume changes which represent the changes in the social status of the bride, but also they reveal the influences of other cultures through trade, migration or colonization. These ceremonies are unique survivals of the traditional costume as most countries have incorporated the "tradition" of the white wedding dress sometime during the 20th century. There are many cases of synthesis between western and local traditional elements in wedding dresses, either in style, fabrics, or accessories (Historic Costume \& Textiles Collection, 1998).

A certain color has different meanings in different cultures. The cultural context of each color is very important. Apart from the traditional concepts the colors symbolize the communication carried between cultures and international marketing. So in Russia the wedding color is the yellow, as it is in South Korea where the yellow symbolizes the joy and happiness and it is used in the garments of Engagement. In India, the bridal bindi is red, because this color symbolizes fertility (De Bortoli \& Maroto, 2001).

\subsection{The Symbolism of Green Color in Wedding Dress}

In Hungary the color green is associated with positive emotions such as hope and expectation and the song that is sung at Hungarian weddings applauds the color green of the wedding dress: "The color green is the hope for success" (Honko, Timonen, \& Branch, 1993). On the contrary green is the color of misfortune in Britain and Ireland and it is shunned by most people at weddings and especially in Scotland, where they avoid even to serve green vegetables in their wedding meals. There are the Scottish stereotyped expressions "Green is not worn at weddings" ka। "'Buy a green dress and your next will be black for mourning... Never, never wear green for your wedding". But this very strong connection between green and unhappiness in marriage, obviously did not exist in the 17th century, when the bride who married Charles I wore a green wedding dress. The explanation for the prevalence of this idea is maybe located in the belief that "witches wear green aprons" or that green symbolizes the loss of virginity or pregnancy (Hutchings, 1997).

\section{Conclusions}

Today, 200 years since the media and entertainment began to promote the white wedding dresses, most women prefer to accept and continue a tradition that celebrates the romantic love and the fairytale beauty of the bride, although it has its roots in the materialistic and empirical world of advertising. There is of course skepticism, the independence of women has increased, the moral attitudes are changing, but the preference in a traditional white wedding dress has increased.

The white wedding dress is a relatively recent tradition in the West and its deviations from the rule are few and powerful declarative. But and within the narrow confines of the typical "white wedding", there is room for the bride to show her personality and showcase her femininity. The white wedding dress prevailed almost throughout the world and especially where there is a strong influence from Europeans and North Americans. There are attempts to revive traditional styles of wedding dresses but usually in these cases there is a mixture of local traditional with western elements.

\section{References}

De Bortoli, M., \& Maroto, J. (2001). Colours Across Cultures: Translating Colours in Interactive Marketing Communications. European Languages and the Implementation of Communication and Information Technologies. Outwith: University of Paisley.

Ehrman, E. (2011). The Wedding Dress: 300 Years of Bridal Fashions. New York: Harry N. Abrams.

Emrich, D. (1970). The Folklore of Weddings and Marriage. New York: Mc Graw-Hill.

Historic Costume \& Textiles Collection. (1998). Wedding Traditions. Colombus: The Ohio State University.

Honko, L., Timonen, S., \& Branch, M. (1993). The Great Bear. Helsinki: Suomalaisen Kirjallisuuden Seura.

Howard, V. (2008). Brides, Inc.: American Weddings and the Business of Tradition. Philadelphia: University of Pennsylvania Press.

Hutchings, J. (1997). Folklore and Symbolism of Green. Folklore Society , 108 (2), pp. 55-63.

Ingrassia, C. (2007). Diana, Martha and Me. In C. Curran, Altared: Bridezillas, Bewilderment, Big Love, Breakups, and What Women Really Think About Contemporary Weddings (pp. 24 - 30). New York: Vintage Books.

Martin, J. (2011). Miss Manners' Guide to Excruciatingly Correct Behavior. New York: W. W. Norton and Company.

McBride-Mellinger, M. (1993). The Wedding Dress. New York: Random House.

Monger, G. (2004). Marriage Customs of the World: From Henna to Honeymoons. Santa Barbara: ABC-CLIO.

Murray, M. (2011). The Black Wedding Dress. Art Monthly Australia , 242 (2), pp. 40 - 42.

Olian, J. (1994). Wedding Fashions, 1862-1912. New York: Dover Publications.

Otnes, C., \& Pleck, E. (2003). Cinderella Dreams: The Allure of the Lavish Wedding. Berkley: University California Press.

Paul, \& Sheryl. (2000). The Conscious Bride: Women Unveil Their True Feelings about Getting Hitched. Oakland: New Harbinger 
Publications.

Seng, Y., \& Wass, B. (1995). Traditional Palestinian Wedding Dress as a Symbol of Nationalism. In J. Eicher, Dress and Ethnicity: Change Across Space and Time (pp. 227 - 253). New York: Berg.

Suga, M. (2003). Packaged in Japan: Elite Wedding in Osaka. In H. Foster, \& D. Johnson, Wedding Dress Across Cultures (pp. 39 - 52). New York: Berg.

Walsh, K. (2005). "You just nod and pin and sew and let them do their thing": An Analysis of the Wedding Dress as an Artifact and Signifier. Ethnologies, 27 (2), pp. 239-259. 